\title{
Studi Timbulan Dan Komposisi Sampah Di Kampus Universitas Lampung
}

\author{
Puspita Yuliandari a ${ }^{\text {Erdi Suroso }}{ }^{\mathrm{b}}$, Pramita Sari Anungputri ${ }^{\mathrm{c}}$
}

Program Studi Teknologi Industri Pertanian, Jurusan Teknologi Hasil Pertanian Fakultas Pertanian Universitas Lampung, Bandar Lampung, 35141

email korespondensi: a puspita.yuliandari@fp.unila.ac.id, berdi.suroso@fp.unila.ac.id, cpramita.sari@fp.unila.ac.id

\begin{abstract}
University of Lampung with an area of 63.5 hectares still has problems in handling waste. The increase in the amount of waste occurred along with the increasing number of residents of the University of Lampung campus. The rate of generation and composition of the waste is not yet known. The purpose of this study is to assess the generation, composition and plan of the concept of waste management at the University of Lampung Campus which consists of five aspects that influence each other, namely operational technical aspects, regulations, institutions, costs and participation of campus residents. Measurement of waste generation uses load count analysis method with samples originating from the University of Lampung campus environment. The waste composition is determined and analyzed based on SNI 19-3964-1994. The results of the study were the rate of waste generation in the University of Lampung at sebesar $770 \mathrm{~kg} /$ day. The largest composition of waste is dominated by compostable waste, plastic, and paper.
\end{abstract}

Keywords: composition, rate of generation, management, waste

\begin{abstract}
Abstrak. Universitas Lampung dengan luas 63,5 hektar masih memiliki permasalahan dalam penanganan sampah. Peningkatan jumlah sampah terjadi seiring dengan bertambahnya jumlah warga kampus Universitas Lampung. Angka laju timbulan dan komposisi sampah belum diketahui secara pasti. Tujuan dari penelitian ini adalah mengkaji timbulan, komposisi dan merencanakan konsep pengelolaan sampah Kampus Universitas Lampung yang terdiri dari lima aspek yang saling mempengaruhi satu sama lainnya yaitu aspek teknik operasional, peraturan, kelembagaan, biaya dan peran serta warga kampus. Pengukuran timbulan sampah menggunakan metode load count analysis dengan sampel yang berasal dari lingkungan kampus Universitas Lampung. Komposisi sampah ditentukan dan dianalisis berdasarkan SNI 19-3964-1994. Hasil penelitian berupa laju timbulan sampah di lingkungan Universitas Lampung sebesar $\pm 770 \mathrm{~kg} / \mathrm{hari}$. Komposisi sampah paling besar didominasi oleh sampah yang dapat dikomposkan, plastik, dan kertas.
\end{abstract}

Kata kunci: komposisi, laju timbulan, pengelolaan, sampah

\section{Pendahuluan}

Sampah adalah bahan buangan dari kegiatan rumah tangga, komersial, industri atau aktivitas-aktivitas yang dilakukan manusia. Sampah juga merupakan hasil sampingan dari aktivitas manusia yang sudah tidak digunakan [1]. Universitas merupakan tempat mahasiswa dan kaum intelektual berkumpul. Universitas merupakan tempat mahasiswa mampu menjadi pribadi yang kreatif dengan minat dan kemampuan yang dimilikinya. Universitas adalah tempat yang tidak hanya sebagai tempat belajar namun riset dan juga mengabdi baik itu untuk masyarakat sekitar ataupun negara [2]. Sampah menjadi salah satu masalah yang serius di lingkungan kampus Universitas Lampung, dengan penyebab utamanya adalah kurangnya lahan untuk TPA, kurangnya dana, dan kurangnya fasilitas yang disediakan [3]. Luas Universtas Lampung yaitu 63,5 hektar yang terbagi dalam 8 fakultas yaitu Fakultas Pertanian (FP), Fakultas Hukum (FH), Fakultas Ekonomi dan Bisnis (FEB), Fakultas Keguruan dan IImu Pendidikan (FKIP), Fakultas 
Matematika dan IImu Pengetahuan Alam (FMIPA), Fakultas IImu Sosial dan IImu Politik (FISIP), Fakultas Teknik (FT), dan Fakultas Kedokteran (FK) [4].

Universitas Lampung memiliki 8 fakultas dan berbagai fasilitas pendukung kegiatan perkuliahan yang tiap aktivitasnya berbeda antara satu dengan yang lain. Perbedaan aktivitas tersebut memungkinkan untuk menghasilkan timbulan, komposisi dan karakteristik sampah yang berbeda pula. Sampah yang ditimbulkan di Kampus Universitas Lampung dikelola secara individu pada tiap-tiap unit atau jurusan di masing masing fakultas. Pengelolaannya meliputi pewadahan, pengumpulan, dan pembakaran di area terbuka tanpa penanganan lebih lanjut. Dengan adanya pembakaran sampah di area terbuka secara tak terkendali seperti itu, akan mengakibatkan polusi udara, mengganggu pernafasan dan estetika. Untuk mencegah terjadinya gangguan terhadap lingkungan dan kesehatan manusia, perlu dirancang suatu sistem pengelolaan persampahan yang baik dan lengkap sesuai dengan Pasal 22 UU Nomor 18 Tahun 2008 tentang Pengelolaan Sampah. Pengelolaan sampah harus berdasarkan data timbulan dan komposisi sampah yang ada [5]. Berdasarkan jenis kegiatan, sumber sampah Kampus Unila dibagi menjadi 2 area yaitu area kuliah-kantor dan area kebun-jalan. Sampah di kedua area tersebut masih belum dikelola dengan baik, hanya ditimbun dan dibakar untuk mengurangi volume timbulannya [6]. Berdasarkan pertimbanganpertimbangan tersebut, maka diperlukan suatu konsep pengelolaan sampah Kampus Universitas Lampung yang terdiri dari lima aspek yang saling mempengaruhi satu sama lainnya yaitu aspek teknik operasional, peraturan, kelembagaan, biaya dan peran serta warga kampus.

\section{Metode Penelitian}

Data yang digunakan pada penelitian ini terdiri atas dua buah jenis yaitu data primer dan data sekunder. Data primer didapatkan dari pengamatan langsung ke lapangan. Pengamatan dilakukan dengan pengukuran langsung timbulan dan komposisi sampah serta penyebaran kuisioner pada petugas kebersihan di lingkungan Universitas Lampung. Data sekunder meliputi SNI 19-3964-1994, SNI 19-2454-2002, SNI 3242:2008, PP No. 81 tahun 2012, Peraturan dan Lampiran I Menteri Pekerjaan Umum No. 3 Tahun 2013, Materi Bidang Sampah (Direktorat Jendral Cipta Karya, Direktorat PLP), PP dan Lampiran No. 101 tahun 2014 Tentang Pengelolaan Limbah Bahan Berbahaya dan Beracun. Pengukuran timbulan sampah berdasarkan penyebaran kuisioner pada petugas kebersihan di lingkungan Universitas Lampung. Pengambilan data dilaksanakan selama 8 hari sesuai yang tercantum dalam SNI 19-3964-1994 tentang metode pengambilan dan pengukuran sampel timbulan dan komposisi sampah perkotaan [6]. Area yang dijadikan titik sampling pengambilan data timbulan dan komposisi sampah meliputi 8 fakultas yang ada di Universitas Lampung, Gedung Serba Guna Unila (GSG Unila), dan area kebun-jalan Unila. Data komposisi sampah didapatkan dari penyebaran kuisioner pada petugas kebersihan di lingkungan Universitas Lampung. Klasifikasi komposisi sampah pada kuisioner dibagi menjadi sampah organik, sampah anorganik, dan sampah B3. 


\section{Hasil dan Pembahasan}

\section{a. Timbulan Sampah}

Timbulan sampah di lingkungan Universitas Lampung dibedakan menjadi dua jenis yaitu sampah organik dan sampah anorganik. Data persentase jumlah sampah organik dan anorganik diperoleh dari rata-rata jawaban petugas kebersihan dari kuisioner yang disebarkan. Berdasarkan perhitungan rata-rata persentase sampah organik dan anorganik diperoleh timbulan sampah organik sebesar $65,34 \%$ dengan berat 503,118 $\mathrm{kg}$ dan timbulan sampah anorganik sebesar $34,66 \%$ dengan berat 266,882 $\mathrm{kg}$ serta berat total sampah perhari adalah $770 \mathrm{~kg}$.

Satu kotak sampah kecil berisi $\pm 4,4$ kg sampah per hari. Satu karung sampah berisi $\pm 19,5 \mathrm{~kg}$ sampah per hari. Satu tong sampah besar berisi $\pm 18 \mathrm{~kg}$ sampah per hari. Satu tossa berisi 6 tong sampah besar. Berat tossa yang berisi 6 tong sampah besar adalah \pm 110 kg (Tabel 1). Setiap hari, ada tujuh kali pengangkutan dengan menggunakan tossa sehingga berat sampah yang terdapat di lingkungan Universitas Lampung adalah $\pm 770 \mathrm{~kg} / \mathrm{hari}$. Timbulan sampah ini berasal dari aktivitas kegiatan belajar mengajar setiap harinya di lingkungan Universitas Lampung. Proses pengumpulan sampah dilakukan selama \pm 8 hari, sumber sampah berasal dari masyarakat kampus, yaitu dosen, staf, dan mahasiswa [7]. Selain itu, ada sampah yang mendominasi yaitu dedaunan dan sisa bangunan mengingat di Kampus Universitas Lampung terdapat banyak pepohonan hijau dan kegiatan konstruksi. Sampah - sampah tersebut dimasukkan dalam trashbag hitam berukuran 90×120 cm lalu ditimbang menggunakan timbangan dengan kapasitas $15 \mathrm{~kg}$.

Pewadahan individual merupakan aktivitas penanganan penampungan sampah sementara dalam suatu wadah khusus untuk dan dari sampah individu [7]. Pewadahan individual di lingkungan Universitas Lampung menggunakan kotak sampah kecil, dan tong sampah besar yang sudah sesuai dengan SNI 3242:2008. Pewadahan komunal merupakan aktivitas penanganan penampungan sampah sementara dalam suatu wadah bersama baik dari berbagai sumber maupun sumber umum [8]. Pewadahan komunal di lingkungan Universitas Lampung menggunakan tossa.

\section{b. Komposisi Sampah}

Komposisi sampah didapatkan dari hasil kuisioner yang telah disebarkan pada petugas kebersihan di lingkungan sekitar Universitas Lampung, kemudian dinyatakan dalam bentuk persentase (\%) (Tabel 2).

Tabel 1. Jenis, berat dan total sampah (kg/hari) di Universitas Lampung

\begin{tabular}{|c|c|c|}
\hline $\begin{array}{l}\text { Jenis Wadah } \\
\text { Sampah }\end{array}$ & $\begin{array}{l}\text { Berat } \\
\text { Sampah } \\
\text { (kg/hari) }\end{array}$ & Keterangan \\
\hline $\begin{array}{l}1 \text { kotak sampah } \\
\text { kecil }\end{array}$ & $\pm 4,4$ & \multirow{3}{*}{$\begin{array}{l}7 \text { kali } \\
\text { pengangkutan } \\
\text { setiap harinya } \\
\text { dengan } \\
\text { menggunakan } \\
\text { tossa } \\
=7 \times 110 \mathrm{~kg} \\
=770 \mathrm{~kg}\end{array}$} \\
\hline $\begin{array}{l}1 \text { tong sampah } \\
\text { besar }\end{array}$ & \pm 18 & \\
\hline $\begin{array}{l}1 \text { tossa ( } \pm 6 \text { tong } \\
\text { sampah besar) }\end{array}$ & \pm 110 & \\
\hline & $\begin{array}{l}\text { Total } \\
\text { sampah } \\
\text { (kg/hari) }\end{array}$ & \pm 770 kg/hari \\
\hline
\end{tabular}


Tabel 2. Komposisi dan persentase sampah (\%) di Universitas Lampung

\begin{tabular}{ll}
\hline Komposisi Sampah & $\begin{array}{l}\text { Persentase } \\
\text { Sampah (\%) di } \\
\text { Lingkungan } \\
\text { Universitas } \\
\text { Lampung }\end{array}$ \\
\hline Dapat dikomposkan & $62 \%$ \\
\hline Plastik & $33,16 \%$ \\
\hline Kertas & $3,34 \%$ \\
\hline B3 & $0,1 \%$ \\
\hline Lain-lain & $1,4 \%$ \\
\hline Total & $100 \%$ \\
\hline
\end{tabular}

Komposisi sampah di lingkungan Universitas Lampung yang paling besar adalah sampah dikomposkan, dengan jumlah persentase $62 \%$. Sampah dapat dikomposkan memiliki jumlah komposisi paling besar karena aktivitas dan kegiatan belajar yang dilakukan di Kampus Universitas Lampung setiap harinya akan menghasilkan sampah yang dapat dikomposkan. Sampah berupa makanan sisa mampu menyebabkan sampah menjadi berat dikarenakan sampah ini memiliki kandungan air yang cukup besar. Sampah - sampah yang berupa sampah kebun dan sampah sisa makanan masih banyak jumlahnya karena tidak ada tahap pengolahan sampah lebih lanjut menjadi bentuk lain, misalnya menjadi kompos.

Menurut [9], teknik operasional pengelolaan sampah perkotaan meliputi pewadahan sampah, pengumpulan sampah, pemindahan sampah, pengangkutan sampah, pengolahan dan pemilahan sampah, serta pembuangan akhir sampah. Pewadahan sampah di Universitas Lampung telah sesuai dengan SNI 3242:2008 [8] dengan menerapkan sistem pewadahan individual meliputi kotak sampah kecil dan tong sampah besar serta pewadahan komunal yang menerapkan penggunaan tossa. Pengumpulan, pemindahan dan pengangkutan sampah yang diterapkan oleh Universitas Lampung adalah dengan menggunakan tong-tong sampah besar serta diangkut secara rutin dua kali dalam sehari yaitu pagi dan sore hari untuk dibawa ke tempat pembuangan sementara (TPS) yang terletak di belakang perpustakaan kampus menggunakan tossa serta pengangkutan menuju tempat pembuangan akhir (TPA) yaitu TPA Bakung, Teluk Betung menggunakan truk. TPS yang digunakan di Universitas Lampung tidak dilengkapi dengan syarat mendasar dari klasifikasi TPS berdasarkan SNI 3242:2008 [8] yaitu adanya ruang pemilahan dan gudang.

Pemilahan sampah adalah proses pemilahan sampah berdasarkan jenis sampah yang dilakukan sejak dari sumber sampai dengan pembuangan akhir [8]. Aktivitas pemilahan sampah di Universitas Lampung hingga saat ini belum diterapkan. Seluruh jenis sampah baik sampah jenis organik maupun anorganik dijadikan dalam suatu wadah tanpa ada label atau tempat pembeda. Tidak hanya pemilahan, pengolahan sampah juga belum diterapkan. Bila dibandingkan dengan SNI 3242:2008 dilakukan pengolahan sampah yang meliputi teknik Reuse, Reduce, dan Recycle di sumber dan TPS [8]. Berdasarkan Peraturan Pemerintah RI No. 81 Tahun 2012 bahwa setiap orang dan pengelola kawasan fasilitas umum melakukan penanganan sampah salah satunya yaitu pengolahan sampah yang meliputi pemadatan, pengomposan dan pendauran ulang [10]. Dilihat dari ulasan diatas bahwa, kampus Universitas Lampung belum memiliki standar penanganan sampah yang baik, karena tidak adanya proses pengolahan sampah lebih lanjut baik melalui tahap pemadatan, pengomposan dan 
pendauran ulang. Pembuangan akhir sampah dari TPS yang terletak di belakang perpustakaan kampus menuju TPA Bakung, Teluk Betung dilakukan rutin selama sekali dalam seminggu menggunakan truk.

Warga Universitas Lampung masih banyak yang belum melaksanakan kewajiban pengelolaan sampah seperti yang diatur dalam Pasal 12 Ayat 1 Undang Undang Nomor 18 Tahun 2008 tentang Pengelolaan Sampah, yang berbunyi "Setiap orang dalam pengelolaan sampah rumah tangga dan sampah sejenis sampah rumah tangga wajib mengurangi dan menangani sampah dengan cara yang berwawasan lingkungan." [11]. Masih banyak warga Universitas Lampung yang membuang sampah tidak pada tempat yang seharusnya. Sampai saat ini Pemerintah Kota Bandar Lampung belum memiliki Perda mengenai pengelolaan sampah terpadu sebagai pengejawantahan peraturan tersebut. Meskipun oleh Pemerintah Pusat semua daerah diwajibkan segera menyusun regulasi sebagai tindak lanjut UU No. 18 Tahun 2008 dan Permendagri No. 33 Tahun 2010 tentang Pengelolaan Sampah. Hal ini berimplikasi terhadap pola pengelolaan sampah yang belum sesuai dengan ketentuan baik pola pengelolaan maupun cara pengolahan.

Kelembagaan pengelolaan sampah di Bandar Lampung terdiri dari Dinas Kebersihan dan Pertamanan, Dinas Pasar, Dinas Perhubungan, Dinas Pekerjaan Umum, Kecamatan, Kelurahan, UPT TPA Bakung dibawah koordinasi Dinas Kebersihan dan Pertamanan Kota Bandar Lampung. Kelembagaan pengelola sampah di Bandar Lampung masih dilakukan secara sendiri-sendiri oleh beberapa dinas serta kecamatan. Kondisi ini juga belum diperkuat dengan model kerja sama antar instansi sehingga terkesan masih sendiri-sendiri [12]. Oleh karena itu, sebaiknya lembaga-lembaga pengelolaan sampah bekerja sama dengan baik agar dapat mengelola sampah di Bandar Lampung dengan baik, termasuk di Universitas Lampung.

Peran serta warga Universitas Lampung dalam pengelolaan sampah diperlukan untuk memudahkan pelaksanaan operasional pengelolaan sampah. Hal ini sesuai dengan Kesuma (2011) bahwa adanya peran serta masyarakat yang baik dalam pengelolaan sampah akan memudahkan pelaksanaan operasional di lapangan dan bahkan dapat menurunkan biaya pengelolaan. Pola kemitraan antara pemerintah kota, swasta dan masyarakat menjadi prioritas karena hasil program kebersihan lingkungan akan dapat dicapai jika adanya kerjasama antara stokeholders tersebut [13]. Lima aspek pengelolaan sampah Kampus Universitas Lampung benar-benar saling mempengaruhi satu sama lainnya yaitu aspek teknik operasional, peraturan, kelembagaan, biaya dan peran serta warga kampus.

\section{Kesimpulan}

Kesimpulan dari studi ini adalah konsep pengelolaan sampah Kampus Universitas Lampung terdiri dari lima aspek yang saling mempengaruhi satu sama lainnya yaitu aspek teknik operasional, peraturan, kelembagaan, biaya dan peran serta warga kampus. Aspek teknik operasional pengelolaan sampah di Universitas Lampung yaitu pewadahan sampah di Universitas Lampung telah sesuai dengan SNI 3242:2008 yaitu pewadahan individual dan komunal, TPS yang digunakan di Universitas Lampung tidak dilengkapi 
dengan syarat mendasar dari klasifikasi TPS berdasarkan SNI 3242:2008 yaitu adanya ruang pemilahan dan gudang, Universitas Lampung belum memiliki standar penanganan sampah yang baik karena tidak adanya proses pengolahan sampah lebih lanjut baik melalui tahap pemadatan, pengomposan dan pendauran ulang. Konsep pengelolaan sampah Kampus Universitas Lampung terdiri dari lima aspek yang saling mempengaruhi satu sama lainnya dan tidak dapat dipisahkan yaitu aspek teknik operasional, peraturan, kelembagaan, biaya dan peran serta warga kampus. Kelembagaan pengelolaan sampah, peraturan tentang pengelolaan sampah, dan peran serta warga Universitas Lampung dalam pengelolaan sampah diperlukan untuk memudahkan pelaksanaan operasional pengelolaan sampah dan menurunkan biaya pengelolaan sampah.

\section{Ucapan Terimakasih}

Ucapan terimakasih terutama ditujukan kepada pemberi dana penelitian atau donatur, serta berbagai pihak yang telah berkerjasama dalam menyelesaikan penelitian ini. Ucapan terimakasih juga ditujukan kepada ananda Silaturahmi Widaputri dan Sherliana Christabella yang telah membantu pelaksanaan penelitian hingga terbitnya jurnal ini.

\section{Daftar Pustaka}

[1] Purwendro dan Nurhidayat. 2006. Mengolah Sampah Untuk Pupuk Pestisida Organik. Penebar Swadaya. Jakarta.

[2] Pusat Penelitian dan Pengembangan Lingkungan Hidup. 2018. Studi Timbulan dan
Komposisi Sampah Kampus Universitas Lampung. Lembaga Penelitian dan Pengabdian Kepada Masyarakat Universitas Lampung. Bandar Lampung.

[3] Dhokhikah, S., Trihadiningrum, Y. dan Sunaryo. 2015. Community participation in household solid waste reduction in Surabaya, Indonesia. Resources, Conservation and Recycling.

[4] Profil Universitas Lampung. 2018. Powerpoint.

[5] Damanhuri, E. dan Padmi, T. 2004. Diktat Kuliah Pengelolaan Sampah. ITB. Bandung.

[6] Setiyono. 2005. Potensi Limbah B3 di Wilayah DKI Jakarta dan Strategi Pengelolaannya. JAI Vol. 1, No. 32005.

[7] BSN. 1994. Metode Pengambilan dan Pengukuran Contoh Timbulan dan Komposisi Sampah Perkotaan. SNI 19-3964-1994. Badan Standardisasi Nasional. Jakarta.

[8] BSN. 2008. Pengelolaan Sampah di Permukiman. SNI 3242:2008. Badan Standardisasi Nasional. Jakarta.

[9] BSN. 2002. Tata Cara Teknik Operasional Pengelolaan Sampah Perkotaan. SNI 192454-2002. Badan Standardisasi Nasional. Jakarta.

[10] Presiden Republik Indonesia. 2012. Peraturan Pemerintah RI No. 81 Tahun 2012 Tentang Pengelolaan Sampah Rumah Tangga dan Sampah Sejenis Sampah Rumah Tangga.

[11] Presiden Republik Indonesia. 2008. Undang Undang Nomor 18 Tahun $2008 \quad$ Tentang Pengelolaan Sampah. 
[12] POKJA AMPL Kota Bandar Lampung. Strategi Sanitasi Kota Bandar Lampung. 2015.

[13] Kesuma, R. 2011. Kajian Terhadap Pengelolaan Sampah di Kota Bandar Lampung. Tesis. Universitas Lampung. Bandar Lampung. 
Puspita Yuliandari dkk. : Studi Timbulan Dan Komposisi Sampah

Di Kampus Universitas Lampung 